\title{
Added value of the regionally coupled model ROM in the East Asian summer monsoon modeling
}

\author{
Shoupeng Zhu ${ }^{1,2,3} \cdot$ Armelle Reca C. Remedio $^{2} \cdot$ Dmitry V. Sein $^{4,5} \cdot$ Frank Sielmann $^{6} \cdot$ Fei Ge $^{3,7} \cdot$ Jingwei Xu $^{1}$. \\ Ting Peng ${ }^{1} \cdot$ Daniela Jacob $^{2} \cdot$ Klaus Fraedrich ${ }^{1,3} \cdot$ Xiefei Zhi $^{1}$ (D)
}

Received: 14 June 2019 / Accepted: 3 January 2020

(C) Springer-Verlag GmbH Austria, part of Springer Nature 2020

\begin{abstract}
The performance of the regional atmosphere-ocean coupled model ROM (REMO-OASIS-MPIOM) is compared with its atmospheric component REMO in simulating the East Asian summer monsoon (EASM) during the time period 1980-2012 with the following results being obtained. (1) The REMO model in the standalone configuration with the prescribed sea surface conditions produces stronger low-level westerlies associated with the South Asian summer monsoon, an eastward shift of the western Pacific subtropical high (WPSH) and a wetter lower troposphere, which jointly lead to moisture pathways characterized by stronger westerlies with convergence eastward to the western North Pacific (WNP). As a consequence, the simulated precipitation in REMO is stronger over the ocean and weaker over the East Asian continent than in the observational datasets. (2) Compared with the REMO results, lower sea surface temperatures (SSTs) feature the ROM simulation with enhanced air-sea exchanges from the intensified low-level winds over the subtropical WNP, generating an anomalous low-level anticyclone and hence improving simulations of the low-level westerlies and WPSH. With lower SSTs, ROM produces less evaporation over the ocean, inducing a drier lower troposphere. As a result, the precipitation simulated by ROM is improved over the East Asian continent but with dry biases over the WNP. (3) Both models perform fairly well for the upper level circulation. In general, compared with the standalone REMO model, ROM improves simulations of the circulation associated with the moisture transport in the lower- to mid-troposphere and reproduces the observed EASM characteristics, demonstrating the advantages of the regionally coupled model ROM in regions where air-sea interactions are highly relevant for the East Asian climate.
\end{abstract}

Xiefei Zhi

zhi@nuist.edu.cn

1 Key Laboratory of Meteorological Disasters, Ministry of Education / Collaborative Innovation Center on Forecast and Evaluation of Meteorological Disasters, Nanjing University of Information Science \& Technology, Nanjing 210044, China

2 Climate Service Center Germany, Helmholtz Centre for Materials and Coastal Research, 20095 Hamburg, Germany

3 Max Planck Institute for Meteorology, 20146 Hamburg, Germany

4 Helmholtz Centre for Polar and Marine Research, Alfred Wegener Institute, 27570 Bremerhaven, Germany

5 Shirshov Institute of Oceanology, Russian Academy of Science, Moscow 117997, Russia

6 Meteorological Institute, University of Hamburg, 20146 Hamburg, Germany

7 Plateau Atmosphere and Environment Key Laboratory of Sichuan Province / School of Atmospheric Sciences, Chengdu University of Information Technology, Chengdu 610225, China

\section{Introduction}

Climate models are considered to be important and valid tools in simulating and understanding climate phenomena (Kumar et al. 2015; Paeth et al. 2015). A number of state-of-art climate models have been developed, although the computational resources currently available restrict global climate models (GCMs) to performing global climate simulations on a long timescale with a regular grid at a horizontal resolution of about $200 \mathrm{~km}$ (Lee and Suh 2000; Ngo-Duc et al. 2017). GCMs with such a coarse resolution cannot sufficiently resolve regional processes, especially over complex terrains. As a result, regional climate models (RCMs) with improved physics representations and higher grid resolutions have been increasingly applied to detect local climate information (Ludwig et al. 2017; Ge et al. 2019; Zhu et al. 2020). However, although a large number of modern RCMs have been developed and could be sufficient for many requirements, the feedbacks associated with atmosphere-ocean interactions and local processes with significant impacts on spatial and temporal 
structures of the regional climate (Wang et al. 2006; Pinto et al. 2014) are still poorly, or even not, taken into account in most climate models (Lucas-Picher et al. 2011).

The regional climate model REMO (Jacob 2001; Jacob et al. 2001) has been applied widely in atmospheric researches. Previous evaluations have highlighted the model performance in terms of the basic features of regional climate over several domains (Jacob et al. 2012; Kumar et al. 2014), such as the African area (Paeth et al. 2009; Vondou and Haensler 2017) and South America (Solman et al. 2013). Based on the atmospheric REMO model, the regionally atmosphere-oceancoupled model ROM (REMO-OASIS-MPIOM) has been developed to investigate the regional climate and local processes (Sein et al. 2014; Niederdrenk et al. 2016).

There have been few applications of REMO and ROM to East Asia, where the ocean conditions, especially in the western North Pacific (WNP), function as sources of both heat and moisture and have substantial impacts on the local and surrounding atmospheric circulation systems (Zhang et al. 2015b; $\mathrm{Zu}$ et al. 2019). The East Asian summer monsoon (EASM) is one of the most typical and important components of the climate in this region and affects nearly one-third of the world's population (Xue et al. 2015; Cai et al. 2017; Fan et al. 2018). Thus, the EASM, with its complex spatial and temporal structure, has received increasing attention (Yang et al. 2011; Zhang et al. 2015a; Ge et al. 2017; Fan et al. 2019). As refined numerical simulations of the EASM climatology in global models do not provide satisfactory results, enormous efforts have been made to simulate the EASM using RCMs (Zou and Zhou 2013; Song and Zhou 2014). It has been shown that atmosphere-ocean feedbacks have a crucial role in regulating the development of the Asian monsoon system (Zou et al. 2016). Therefore, the explicit inclusion of the feedbacks between the atmosphere and ocean is necessary in modeling the EASM system and understanding the underlying mechanisms.

In this study, the climate modeling based on the coupled model ROM and its standalone atmospheric component REMO is carried out at a fine resolution of $50 \mathrm{~km}$ to identify the characteristics of the REMO model and the impacts of the regional atmosphere-ocean coupling in reproducing the EASM system. The numerical modeling results are compared with several reanalysis datasets for the boreal summer.

This paper is structured as follows. The "Datasets and modeling" section describes the datasets and the model design. The "Results" section presents the results of the model validation, including the summer precipitation and a simple EASM index. The main mechanism behind the different modeling results from REMO and ROM is also analyzed in the "Results" section, including the moisture transport, atmospheric circulation at different levels, and sea surface conditions. Finally, the "Conclusions and discussion" section follows subsequently.

\section{Datasets and modeling}

\subsection{Observational datasets}

Multiple reanalysis datasets, hereafter termed observations, are used for the model validation. The first is the European Centre for Medium-Range Weather Forecasts interim reanalysis (ERA Interim; Dee et al. 2011) with a resolution of $0.5^{\circ} \times$ $0.5^{\circ}$. The second is the National Centers for Environmental Prediction (NCEP)-Department of Energy (DOE) Reanalysis II dataset (NCEP II; Kanamitsu et al. 2002) with a resolution of $2.5^{\circ} \times 2.5^{\circ}$, which is an improved version of the NCEP Reanalysis I model that fixed errors and updated parameterizations of physical processes. In addition, the Modern-Era Retrospective analysis for Research and Applications Version 2 (MERRA2; Gelaro et al. 2017), the latest atmospheric reanalysis of the modern satellite era produced by the Global Modeling and Assimilation Office (GMAO) of National Aeronautics and Space Administration (NASA) with the $0.5^{\circ} \times 0.625^{\circ}$ resolution, is also employed in the study. Additionally, the Climate Prediction Center Merged Analysis of Precipitation (CMAP; Xie and Arkin 1997) enhanced version (with NCEP Reanalysis) and the Global Precipitation Climatology Project (GPCP; Adler et al. 2003) version 2.3 are used as the reference data for precipitation, both on a $2.5^{\circ} \times 2.5^{\circ}$ global grid. In this study, all statistical significances are performed for the $95 \%$ confidence level using the two-tailed Student's $t$ test.

\subsection{Model components and setup}

The regionally coupled atmosphere-ocean-sea-ice model ROM comprising the atmospheric REgional MOdel (REMO) (Jacob 2001; Jacob et al. 2001), the Max Planck Institute Ocean Model (MPIOM) (Marsland et al. 2003; Jungclaus et al. 2013), and the Hydrological Discharge (HD) model (Hagemann and Dümenil 1997; Hagemann and Gates 2001) is applied to reproduce the climatology of the EASM system. In parallel, the standalone atmospheric model REMO is also performed to investigate impacts of the regional atmosphere-ocean coupling.

The ocean model MPIOM is run in a global configuration, with a regionally high horizontal resolution in Southeast Asia. MPIOM is performed with a curvilinear grid with shifted poles located over land to avoid the numerical singularity associated with the convergence of meridians, so that the model can well reach the regionally high resolution and maintain a global domain. It has 40 vertical levels with increasing level thickness from $10 \mathrm{~m}$ in upper $70 \mathrm{~m}$ to $500 \mathrm{~m}$ in the deep ocean. Moreover, the following parameterizations, aiming at subgrid-scale physical processes, are included: the bottom boundary layer slope convection scheme (Marsland et al. 2003), the isopycnal scheme (Griffies 1998), the Gent and McWilliams 
style parameterization (Gent et al. 1995), and the enhanced vertical diffusion parameterization (Marsland et al. 2003). The model is initialized with the Polar Science Center Hydrographic Climatology (PHC) temperature and salinity (Steele et al. 2001) and is spun up twice for 45 years (19582002) with forcing by the ERA-40 Reanalysis (Uppala et al. 2005). After the ocean spin-up in standalone mode, it is coupled with the REMO model for an additional 45 years (1958-2002). The restart files obtained from this simulation for 31 December 2002 are used as the initial conditions for the ROM spin-up with ERA Interim forcing (an additional 21 years for 1980-2000). Finally, the model state obtained for 31 December $2000(90+45+21$, i.e., 156 years of spinup for the ocean and 66 years for the atmosphere) is used as the initial conditions for our simulations.

The atmospheric model REMO has a horizontal resolution of $50 \mathrm{~km}$ and 27 hybrid vertical levels. The domain mainly covers the WNP and surrounding area, which play crucial rules in the EASM system (Wang et al. 2005), as shown in Fig. 1. A rotated grid is applied in the REMO configuration to avoid the largely different extensions of grid cells close to the poles. The dynamic core of the model and the discretization in space and time are based on the Europa Model of the German Weather Service (Majewski 1991). The physical parameterizations are taken from the GCM ECHAM versions 4 and 5 (Roeckner et al. 1996, 2003). REMO's prognostic variables are the surface pressure, horizontal wind components, temperature, water vapor, liquid water, and cloud ice. The horizontal discretization is performed on the Arakawa-C-grid, and the hybrid vertical coordinates are defined according to Simmons and Burridge (1981). The time discretization is based on the leap frog scheme with semi-implicit correction

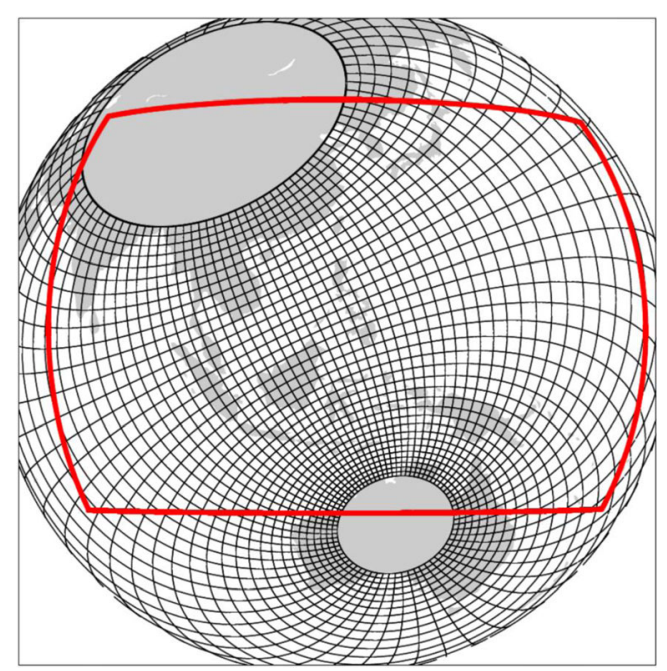

Fig. 1 Model grid configuration taken from Sein et al. (2015). The red rectangle denotes the coupled domain. The black lines are the ocean model grid (only every 12 th grid line is shown). The air-sea fluxes are coupled over the western North Pacific and surrounding area, which play crucial rules in the East Asian summer monsoon system and Asselin filter smoothing (Asselin 1972). For the ocean grid points, the sea surface temperature (SST) and sea ice distribution are prescribed as the lower boundary values. In the uncoupled simulations, they are taken from the ERA Interim reanalysis dataset, whereas from the MPIOM model in the coupled mode. The initial conditions for the REMO model are the state obtained from the 66-year ROM spin-up (see above). The lateral boundary forcing is obtained from the ERA Interim reanalysis for both the standalone and coupled cases.

The terrestrial hydrology model HD is run over the whole globe with constant $0.5^{\circ}$ resolution to simulate the lateral fluxes of freshwater at the land surface. In the model, the total lateral water outflow from a grid box contains three flow processes: overland flow, base flow, and river flow. Detailed information can be found in previous model (Hagemann and Gates 2001).

The coupling is carried out via the Ocean Atmosphere Sea Ice Soil Version 3 (OASIS3) coupler developed by the European Centre for Research and Advanced Training in Scientific Computation (CERFACS; Valcke et al. 2003) with an interval of $3 \mathrm{~h}$. Under the OASIS3 framework, REMO obtains the lower boundary conditions over the sea and sea ice surfaces from the ocean model MPIOM, and provides MPIOM with the atmospheric momentum and the heat and water fluxes. Further details about the model coupling have been reported by Sein et al. (2015).

\section{Results}

\subsection{Simulations of summer precipitation}

Figure 2 presents the spatial distributions of summer precipitation averaged over 1981-2012 extracted from the observations and the models, with their differences shown in Fig. 3. The observations (Fig. 2a, d) are characterized by high precipitation from the Bay of Bengal (BOB) to the Indochina Peninsula (ICP). A clear rain band is seen over the nearequatorial western Pacific, where the ERA Interim and CMAP datasets indicate higher precipitation than the GPCP and MERRA2 datasets.

The coupled model ROM simulation captures the distribution of rainfall well, especially for the center over the BOB and ICP (Fig. 2e). The pattern correlation coefficients (PCCs) between the ROM precipitation and the ERA Interim, CMAP, GPCP, and MERRA2 observations are $0.70,0.55,0.67$, and 0.55 , respectively, all passing the 0.01 significance level. Most biases of the ROM simulation over the continental area are not significant according to Student's $t$ test (Fig. 3a, d). The main deficiency occurs over the near-equatorial western Pacific east of the Philippines, with underestimations of precipitation. 
(a) ERA Interim

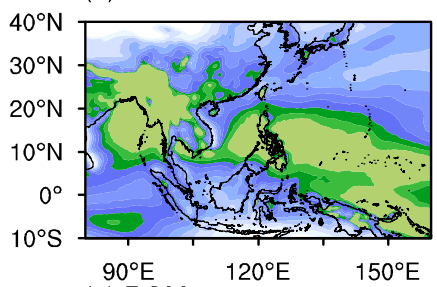

(e) ROM

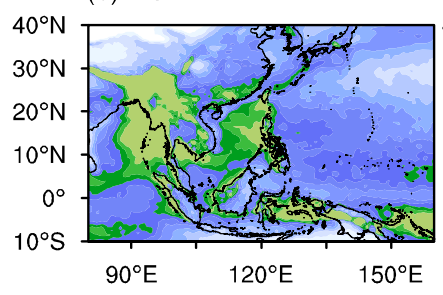

(b) CMAP

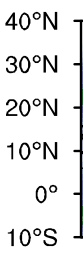

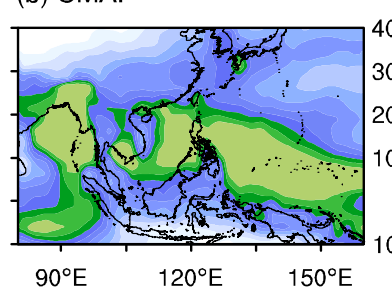

(f) REMO (c) GPCP

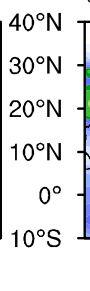

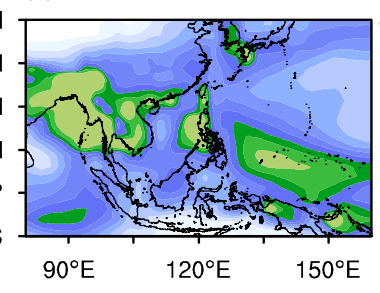

(d) MERRA2

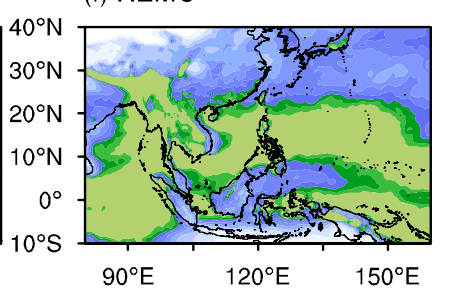

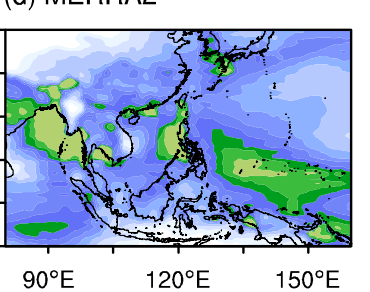

\begin{tabular}{|l|l|l|l|l|l|l|l|l|l|l|}
\hline & & & & & & & & & & \\
\hline
\end{tabular}

Fig. 2 Spatial distributions of the summer daily precipitation (shading, unit mm) derived from (a) ERA Interim, (b) CMAP, (c) GPCP, (d) MERRA2, (e) ROM, and (f) REMO, averaged over the time period 1980-2012

The precipitation simulated by the standalone atmospheric model REMO is characterized by similar patterns to the observations (Fig. 2f), with PCCs of $0.73,0.63,0.59$, and 0.60 for the ERA Interim, CMAP, GPCP, and MERRA2 datasets, respectively, passing the 0.01 significance level. These are

(a) ROM - ERA Interim

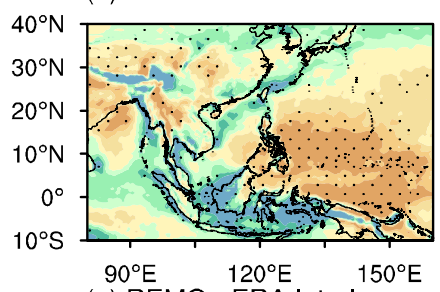

(e) REMO - ERA Interim

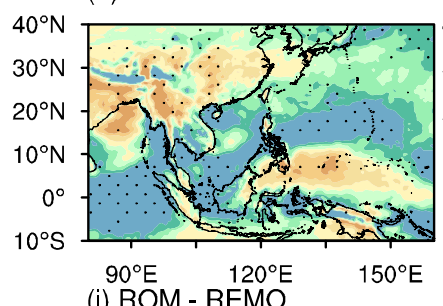

(i) ROM - REMO (b) ROM - CMAP

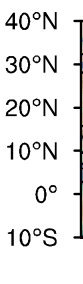

$40^{\circ} \mathrm{N}$
$30^{\circ} \mathrm{N}$
$20^{\circ} \mathrm{N}$
$10^{\circ} \mathrm{N}$
$0^{\circ}$
$10^{\circ} \mathrm{S}$

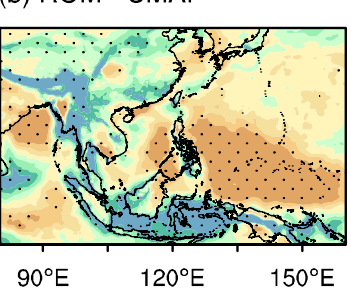

(f) REMO - CMAP

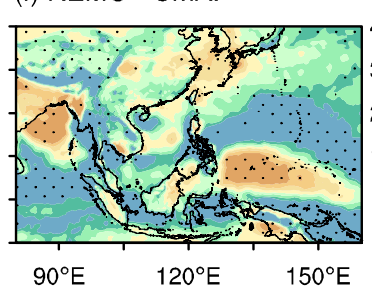

slightly higher than the ROM results, except for the GPCP observation. For the continental areas, REMO produces dry biases over the northern part of East Asia (e.g., the Chinese mainland), but has clear wet biases over the ICP (Fig. 3e, h). In contrast with the underestimated precipitation over the WNP

(c) ROM - GPCP

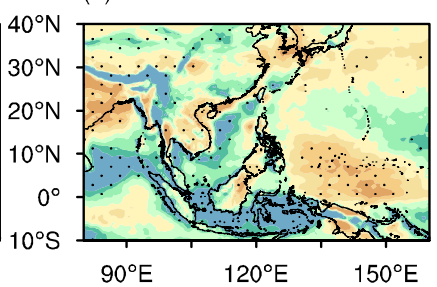

(g) REMO - GPCP

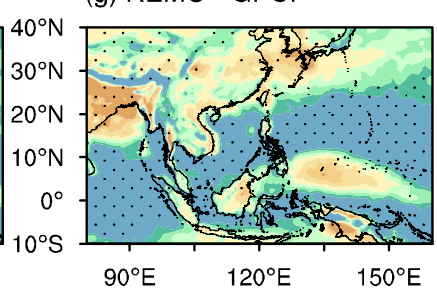

(d) ROM - MERRA2

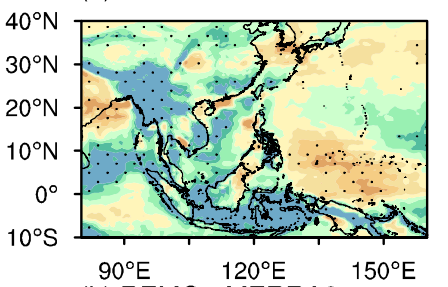

(h) REMO - MERRA2

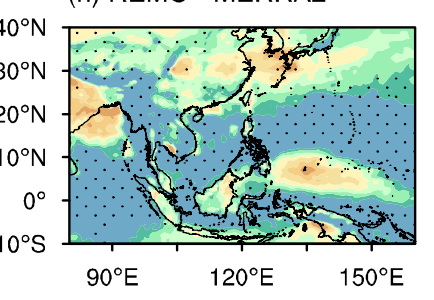

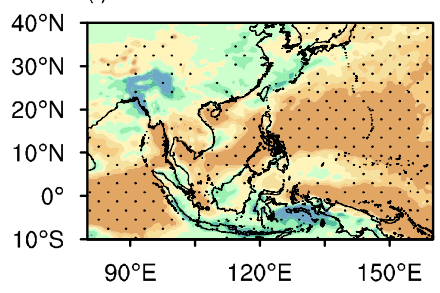

\begin{tabular}{|l|l|l|l|l|l|l|l|}
\hline & & & & & & & \\
\hline-3 & -2 & -1 & 0 & 1 & 2 & 3
\end{tabular}

Fig. 3 Spatial distributions of the differences in summer daily precipitation (shading, unit $\mathrm{mm}$ ) between the model results and observations. a ROM minus ERA Interim. b ROM minus CMAP. c ROM minus GPCP. d ROM minus MERRA2. e REMO minus ERA
Interim. f REMO minus CMAP. g REMO minus GPCP. h REMO minus MERRA2. i ROM minus REMO, averaged over the time period 1980-2012. The black dotted regions indicate the differences exceeding the $95 \%$ confidence level based on Student's $t$ test 
from ROM, REMO tends to produce excessive precipitation with wet biases of up to $3 \mathrm{~mm}$ relative to the observations over the southern BOB and the western Pacific.

In general, both models represent the distribution patterns of the observed summer precipitation over the study area. The coupled ROM simulation reproduces the summer precipitation well, especially over most parts of the continent, but underestimates the precipitation over the ocean. By contrast, the standalone REMO simulation features weaker precipitation over the north East Asia, but higher over the near-equatorial area including the BOB, ICP, and the western Pacific.

\subsection{Simulations of the EASM}

To reveal the model capability to simulate the intensity and variation of the EASM, the EASM index proposed by Wang and Fan (1999; the W-F index hereafter) is calculated in this section. This index is defined by the shear vorticity of the zonal winds:

$$
\begin{aligned}
I= & U_{850 \mathrm{hPa}}\left(5^{\circ}-15^{\circ} \mathrm{N}, 90^{\circ}-130^{\circ} \mathrm{E}\right) \\
& -U_{850 \mathrm{hPa}}\left(22.5^{\circ}-32.5^{\circ} \mathrm{N}, 110^{\circ}-140^{\circ} \mathrm{E}\right)
\end{aligned}
$$

where $U_{850 \mathrm{hPa}}$ is the $u$-component of the horizontal wind velocity at $850 \mathrm{hPa}$. It mainly reflects the two key elements of the EASM circulation system, that is, the WNP monsoon and the subtropical high.

Figure 4 shows the W-F monsoon indices derived from the observations and model simulations. The results from ROM and REMO simulations both reproduce the pronounced interannual variability of the EASM well. The ROM-simulated indices closely resemble those from the observations, but with slightly lower values, whereas the REMO results are characterized by noticeably higher values and larger biases, especially during the 1980s and the early twenty-first century. The temporal correlation coefficients between the index series derived from the ROM simulation and the observations are all about 0.77 , whereas the REMO simulation has a lower

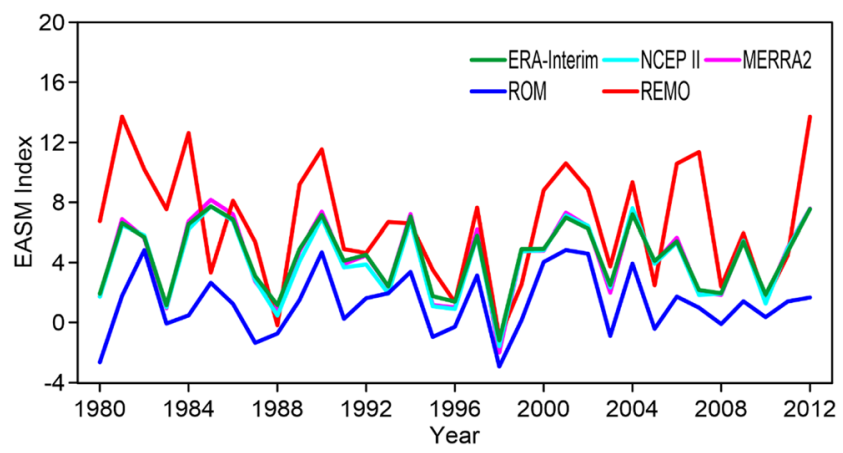

Fig. 4 Time series of the summer mean East Asian summer monsoon (EASM) Wang and Fan (W-F) indices derived from ERA Interim, NCEP II, MERRA2, ROM, and REMO, which are marked by green, turquoise, purple, blue, and red solid lines, respectively, for the time period 1980 2012 correlation coefficient of 0.65 , passing the 0.01 significance level. The results, therefore, suggest that the coupled model ROM performs better in simulating the EASM intensity than the standalone atmospheric model REMO.

\subsection{Main mechanisms controlling the differences in EASM modeling of ROM and REMO}

\subsubsection{Tropospheric moisture transport}

The moisture transport plays an essential role in the EASM system, determining the summer precipitation and influencing both the location and intensity of the monsoon. Figure 5 shows the observed and simulated summer mean tropospheric vertically integrated moisture fluxes and their corresponding divergences averaged over 1980-2012. According to the observations (Fig. 5a, c), there are three typical water vapor sources supplying the East Asian continent, which have also been identified in many studies (Zhu et al. 1986; Ninomiya 1999): Starting from the west, the first is the result of westerly moisture fluxes impacted by the South Asian summer monsoon (SASM), which brings abundant moisture from the BOB, ICP, and the South China Sea into the East Asian continent. The second source mainly comes from southerly moisture fluxes due to cross equatorial flows. The third source is supplied by moisture fluxes over the western Pacific, which can be ascribed to the western Pacific subtropical high (WPSH). The convergence of the three water vapor transport paths lies over a band from southern china to Japan (the brown box in Fig. 5) and extends northeastwards, contributing to the high levels of precipitation alongside these areas.

The ROM model reproduces the moisture pathways and their convergence (Fig. 5d). Compared with the observations, the simulated water vapor fluxes converge with a slightly higher magnitude over some parts of southern and eastern China. By contrast, the lower moisture convergence characterizes the near-equatorial western Pacific. As a result, ROM reproduces the precipitation over the continental area, but with dry biases to the east of the Philippines (Fig. 2e).

In the REMO simulation (Fig. 5e), the southwesterly moisture fluxes from the Indian Ocean associated with the SASM are enhanced relative to the observations, which generates significant wet biases over the BOB and ICP. The southwesterly moisture stretches continuously too far to the east toward the WNP. The simulated water vapor transport heading to the East Asian continent is not as evident as in the observations and the ROM simulation. Correspondingly, the moisture convergence in the REMO model is decreased over the northern part of East Asia, where the rainfall is subsequently underestimated (Fig. 3e, h). The water vapor flows converge over the mid-WNP near $135^{\circ} \mathrm{E}$, leading to wet biases over the western Pacific. 
(a) ERA Interim

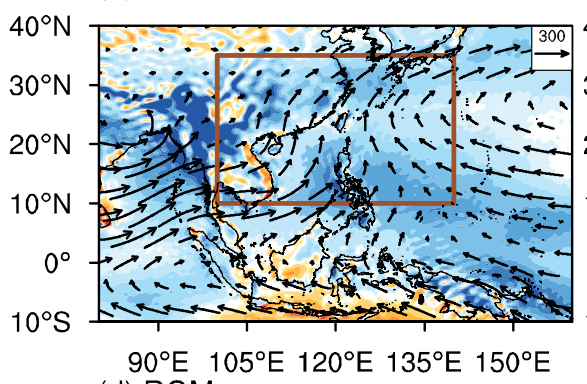

(d) ROM

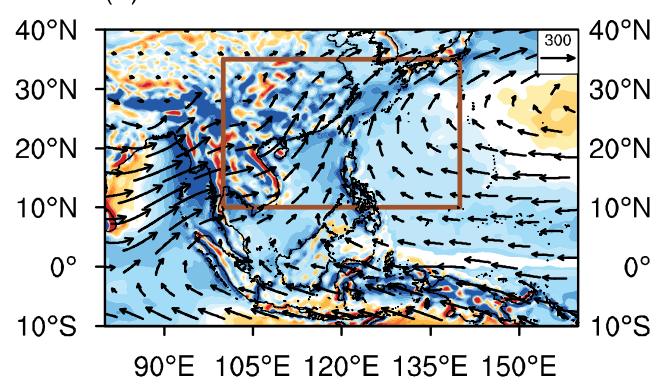

(b) NCEP II

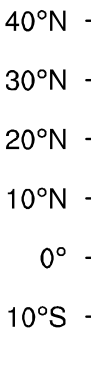

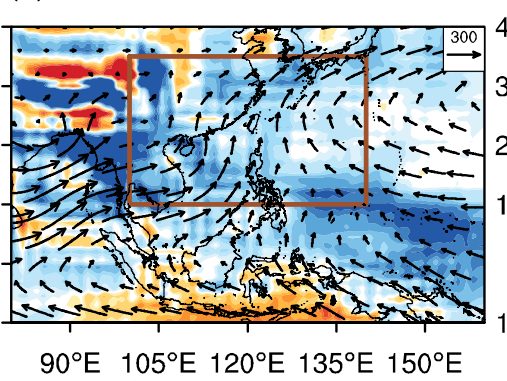

(e) REMO (c) MERRA2

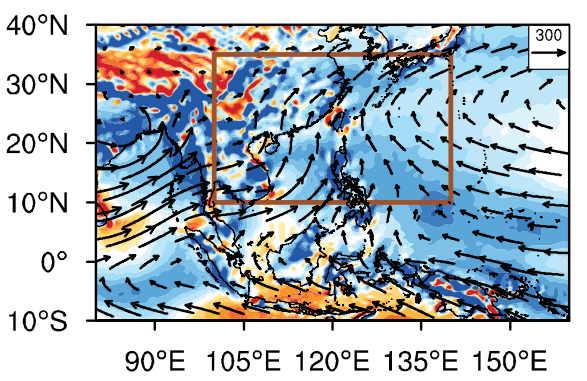

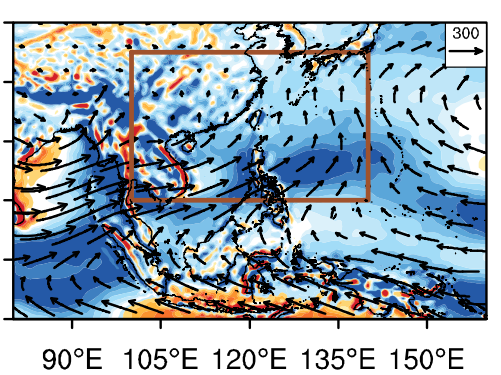

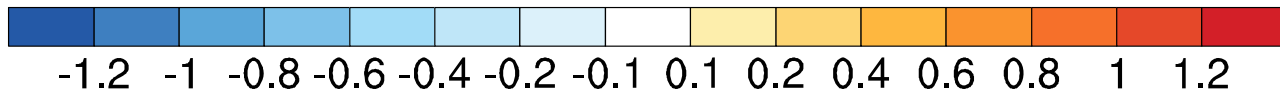

Fig. 5 Spatial distributions of the summer mean tropospheric vertically integrated moisture fluxes (arrows, scale in upper right in $\mathrm{kg} \mathrm{m}^{-1} \mathrm{~s}^{-1}$ ) and the corresponding divergences (shading, units $10^{-4} \mathrm{~kg} \mathrm{~m}^{-2} \mathrm{~s}^{-1}$ ) derived

from (a) ERA Interim, (b) NCEP II, (c) MERRA2, (d) ROM, and (e) REMO, averaged over the time period 1980-2012. The brown box represents the main observed convergence area

After the regional atmosphere-ocean coupling, the extension of water vapor transport related to the SASM, which is exaggerated in the REMO simulation, is no longer seen. The enhanced moisture convergence over the East Asian continent is remarkable in the ROM results, and resembles the observations in terms of both location and intensity. The representative simulated water vapor transport over the whole WNP makes a large contribution to the improvements in simulating summer rainfall over the East Asian continent by the ROM model.

\subsubsection{Atmospheric circulation}

Considering that moisture conditions are mainly dominated by the lower atmosphere, the low-level winds and moisture at $850 \mathrm{hPa}$ are examined in the simulations (Fig. 6). The observed summer mean wind fields (Fig. 6a, c) are characterized by similar features to the moisture transport: the westerlies related to the SASM; the cross-equatorial flows over the maritime continent; and the anticyclonic circulation over the WNP. Flows from the equator move northward through $15^{\circ} \mathrm{N}$ and converge at about $120^{\circ} \mathrm{E}$, leading to the northward monsoon flow along the western edge of the WPSH (brown box in Fig. 6). In the REMO simulation (Fig. 6e), the lowlevel westerlies related to the SASM are excessively strong and shift too far east towards the WNP compared with the observations. Correspondingly, the simulated anticyclone over the WNP at $850 \mathrm{hPa}$ is weak and also retreats eastward. The simulated moisture transport follows the spatial low-level wind patterns. Similar patterns to those in the REMO simulation also occur in simulations performed by many models under the Coupled Model Inter-comparison Project Phase 5 (CMIP5) and several RCMs (Song and Zhou 2014; Zou et al. 2016). By contrast, the observed low-level features are captured well by the coupled ROM model (Fig. 6d). The coupling reduces the westerlies associated with the SASM, which, in the standalone REMO simulation, are located too far east. The simulated low-level southwesterly winds over the East Asian continent become evident, as well as the stronger WNP anticyclone relative to the REMO simulation. The low-level northward monsoon flow along the western edge of WPSH is therefore represented better by the coupled model ROM.

Figure 6 also shows the distributions of the summer mean specific humidity at the low level derived from the observations and model simulations. The ROM simulation produces a drier lower troposphere over the WNP compared with the ERA Interim dataset, but the simulated moisture pattern resembles the other two observational datasets (NCEP II and MERRA2) well. By contrast, the REMO simulation generates wet biases over most areas, especially from the southern $\mathrm{BOB}$ to the eastern Philippines. It indicates that, over this area, the regional atmosphere-ocean coupling reduces the simulated lower tropospheric water vapor content. As a consequence, the representative simulation of the moisture transport over 
(a) ERA Interim

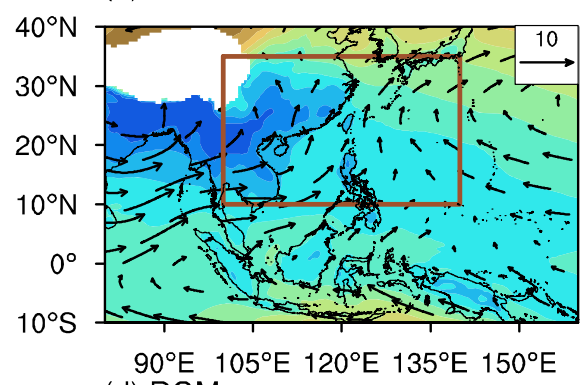

(d) ROM

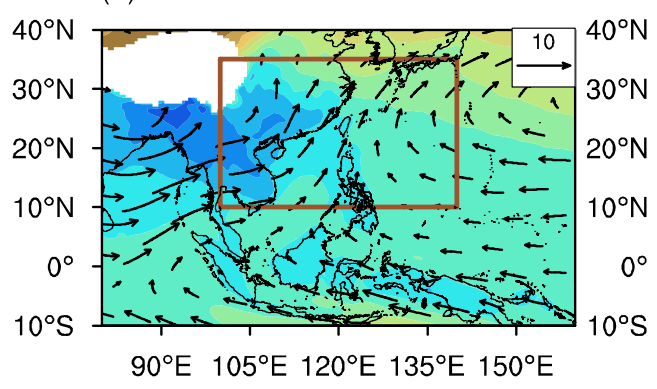

(b) NCEP II

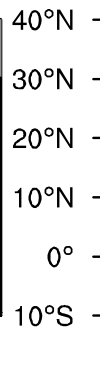

(c) MERRA2

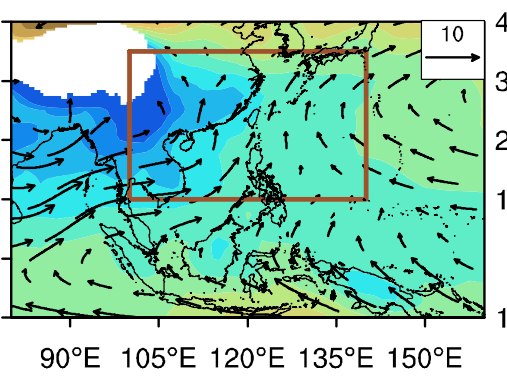

(e) REMO

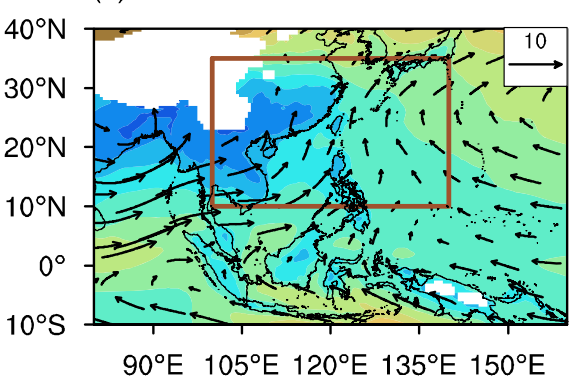

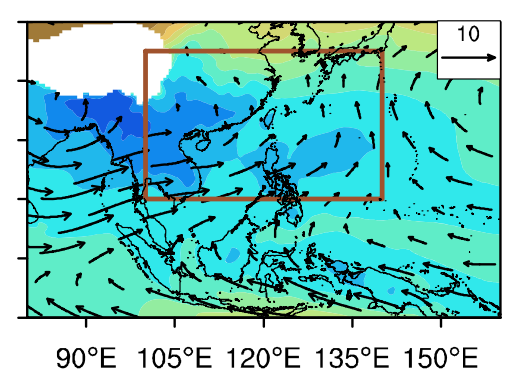

$90^{\circ} \mathrm{E} 105^{\circ} \mathrm{E} 120^{\circ} \mathrm{E} 135^{\circ} \mathrm{E} 150^{\circ} \mathrm{E}$

\begin{tabular}{ll|lll|l|l|lll|l|l|}
\hline & & & & & & & & & & & \\
\hline
\end{tabular}

Fig. 6 As in Fig. 5 but for the wind (arrows, scale in upper right in $\mathrm{m} \mathrm{s}^{-1}$ ) and the specific humidity (shading, unit $\mathrm{g} \mathrm{kg}^{-1}$ ) at $850 \mathrm{hPa}$. The brown box represents the main observed convergence area

East Asia in ROM mainly results from adjustments of both the weaker low-level westerlies and drier lower troposphere compared with the REMO model.

For higher levels above $400 \mathrm{hPa}$, the South Asia high (SAH) dominates the Tibetan Plateau and its surroundings, being strongest and steadiest between 150 and $100 \mathrm{hPa}$. The SAH center in the upper troposphere and the nearby circulation have great impacts on the EASM, together with the atmospheric movements at $850 \mathrm{hPa}$ (Liu et al. 2013). The difference in zonal winds between 850 and $200 \mathrm{hPa}$ is often used to identify the north-south land-sea thermal contrast and to recognize the monsoon intensity (Webster and Yang 1992), which is presented together with the wind fields at $200 \mathrm{hPa}$ in Fig. 7. Both the ROM and REMO simulations reproduce the high-level circulations satisfactorily, particularly the SAH. The PCCs of zonal winds between the simulations and observations are all greater than 0.99 , passing the 0.01 significance level. However, as a result of the stronger $850 \mathrm{hPa}$ westerlies over East Asia in REMO (Fig. 6e), the regions with positive vertical zonal shears cover a larger area over the WNP (expanding eastward to almost $150^{\circ} \mathrm{E}$; Fig. 7e) than in the observations and ROM simulations, which conforms the stronger EASM by REMO (Fig. 4).

In addition to the circulations at low and high levels, the WPSH at $500 \mathrm{hPa}$ also substantially influences the summer monsoon system over East Asia, which is assessed as follows (contours in Fig. 8). The pattern and intensity of the WPSH are reproduced by both the ROM and REMO models. The ROM simulation also resembles the observed western edge of the
WPSH represented by the $5880 \mathrm{gpm}$ line, located in the area of $20^{\circ}-30^{\circ} \mathrm{N}, 135^{\circ}-140^{\circ} \mathrm{E}$. However, the position is shifted eastwards to about $150^{\circ} \mathrm{E}$ by the REMO simulation. The PCCs of the geopotential height at $500 \mathrm{hPa}$ are $0.98,0.99$, and 0.97 between the ROM simulation and the observations of ERA Interim, NCEP II, and MERRA2, respectively, which are of similar magnitude to those for the REMO results $(0.97$, 0.97 , and 0.95 ), all passing the 0.01 significance level. It is suggested that both REMO and ROM can represent the midlevel geopotential height well, whereas ROM is more skillful especially for the WPSH simulation, although the improvement is not as pronounced as that at low levels.

\subsubsection{Sea surface conditions}

According to the above analysis, the superiority of the ROM simulation to the REMO results is increasingly representative as the level decreases. To a great extent, the explicit difference between the two simulations stems from their respective sea surface conditions, which affect the simulated atmospheric circulation and the related moisture transport. The spatial distributions of summer mean sea level pressures (SLPs) and SSTs show the following features. The SLPs of the coupled model ROM (Fig. 8d) are comparable with the reanalysis datasets (Fig. 8a, c), whereas the REMO simulation (Fig. 8e) shows lower values than the observations and ROM simulations, leading to the lower geopotential height in the midtroposphere (Fig. 8e) and the eastward shift of the westerlies (Fig. 6e). 
(a) ERA Interim

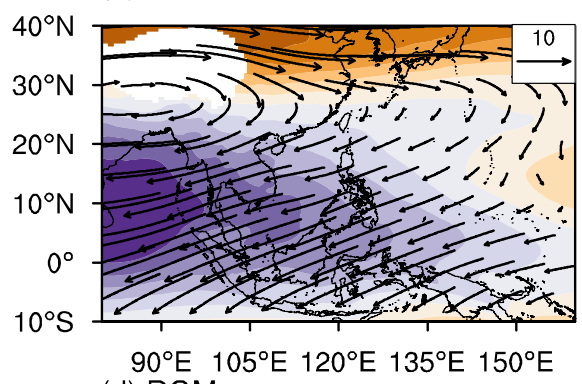
(d) ROM

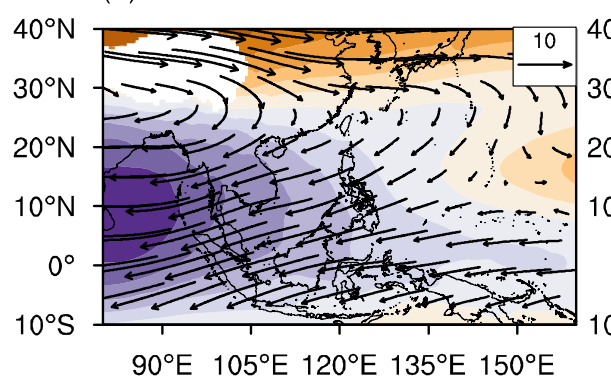

(b) NCEP II

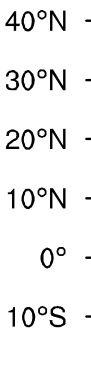

(c) MERRA2

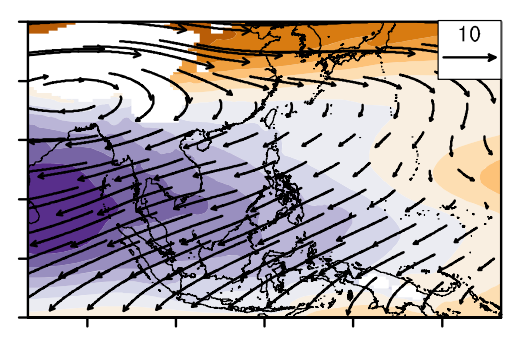

$90^{\circ} \mathrm{E} 105^{\circ} \mathrm{E} 120^{\circ} \mathrm{E} 135^{\circ} \mathrm{E} 150^{\circ} \mathrm{E}$

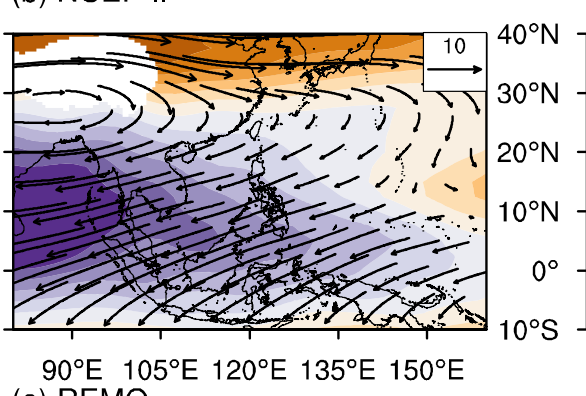

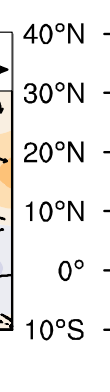

$90^{\circ} \mathrm{E} 105^{\circ} \mathrm{E} 120^{\circ} \mathrm{E} 135^{\circ} \mathrm{E} 150^{\circ} \mathrm{E}$

(e) REMO

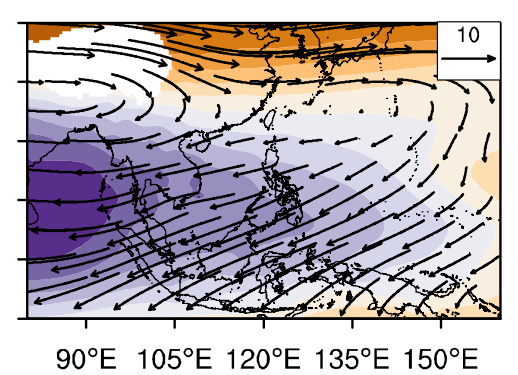

$90^{\circ} \mathrm{E} 105^{\circ} \mathrm{E} 120^{\circ} \mathrm{E} 135^{\circ} \mathrm{E} 150^{\circ} \mathrm{E}$

\begin{tabular}{llllllllllll|l|l|}
\hline & & & & & & & & & & & \\
\hline & -25 & -20 & -15 & -10 & -5 & 0 & 5 & 10 & 15 & 20 & 25
\end{tabular}

Fig. 7 As in Fig. 5 but for the wind (arrows, scale in upper right in $\mathrm{m} \mathrm{s}^{-1}$ ) at $200 \mathrm{hPa}$ and the vertical shear of zonal wind (U850 minus U200, shading, unit $\mathrm{m} \mathrm{s}^{-1}$ )

The distribution of SST differences between the ROM and REMO simulations is characterized by negative values over most of the WNP (Fig. 9), especially to the north of $20^{\circ} \mathrm{N}$, representing lower SSTs in the ROM simulation, which is associated with the enhanced atmosphere-ocean mixing from the intensified low-level wind (Fig. 10) over the subtropical WNP (Cha et al. 2016). Correspondingly, an anomalous lowlevel anticyclone is generated in the WNP, located near southern Japan, which strengthens the simulated WPSH and weakens the low-level westerlies related to the SASM in the (a) ERA Interim

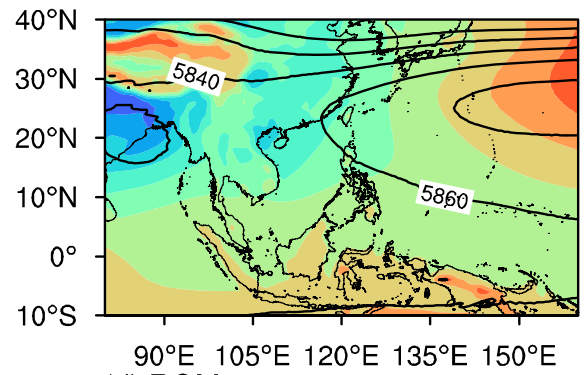

(d) ROM

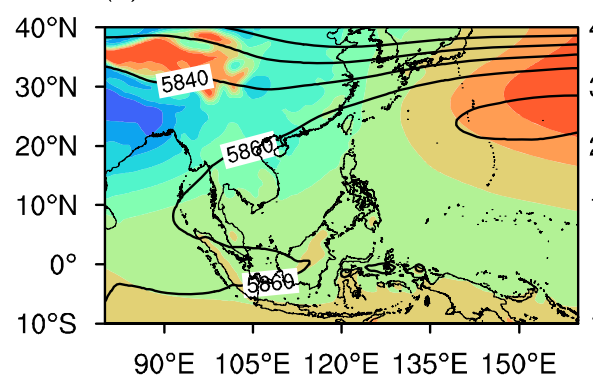

(b) NCEP II

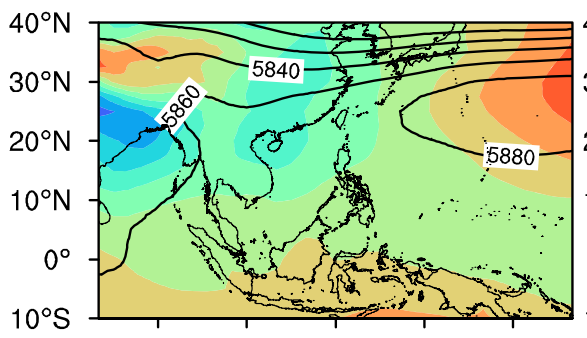

$90^{\circ} \mathrm{E} 15^{\circ} \mathrm{E} 120^{\circ} \mathrm{E} 135^{\circ} \mathrm{E} 150^{\circ} \mathrm{E}$ (e) REMO (c) MERRA2

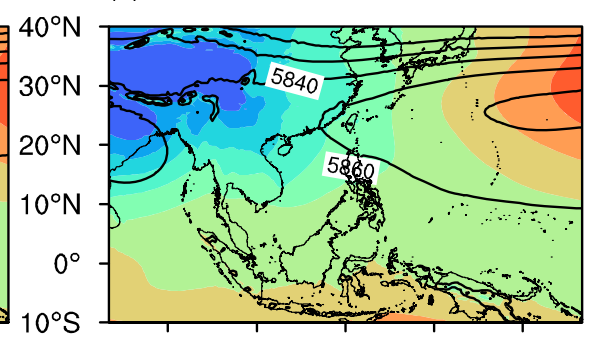

$90^{\circ} \mathrm{E} 105^{\circ} \mathrm{E} 120^{\circ} \mathrm{E} 135^{\circ} \mathrm{E} 150^{\circ} \mathrm{E}$

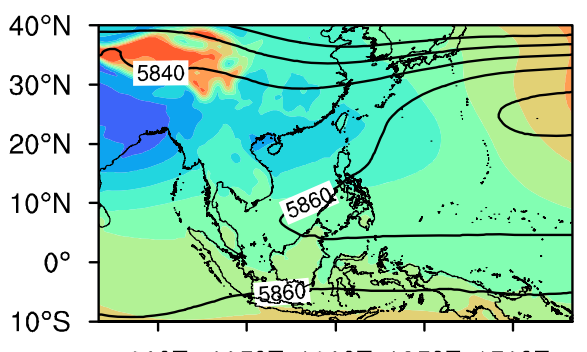

$90^{\circ} \mathrm{E} 105^{\circ} \mathrm{E} 120^{\circ} \mathrm{E} 135^{\circ} \mathrm{E} 150^{\circ} \mathrm{E}$

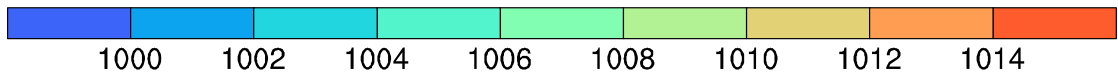

Fig. 8 Spatial distribution of the summer mean geopotential height at $500 \mathrm{hPa}$ (contour, unit $\mathrm{m}$ ) and the summer mean sea level pressure (SLP, shading, unit hPa) derived from (a) ERA Interim, (b) NCEP II, (c) MERRA2, (d) ROM, and (e) REMO, averaged over the time period 1980-2012 
ROM - REMO SST (Shading) \& SLP (Contour)

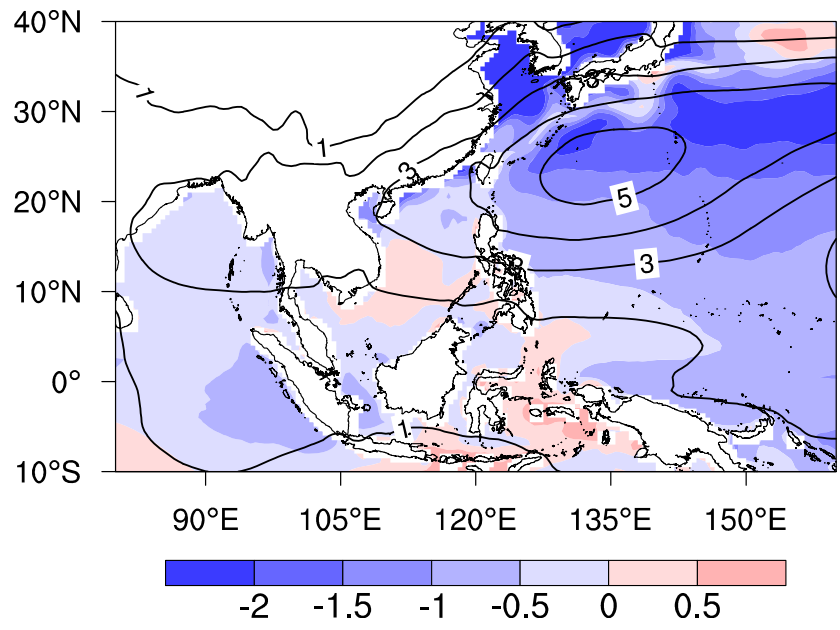

Fig. 9 Differences in the summer mean sea surface temperature (SST, shading, unit ${ }^{\circ} \mathrm{C}$ ) and sea level pressure (SLP, contour, unit hPa) between the ROM and REMO simulations averaged over the time period 19802012

ROM simulation. In addition, the lower SSTs simulated by the ROM model reduce evaporation from the sea surface, leading to a drier lower troposphere over the WNP (Fig. 6d).

The improvement in the large-scale atmospheric circulations in the ROM simulation, particularly in the lower troposphere, is triggered by air-sea flux exchanges between the atmospheric and ocean models and represents a better consistency with the atmospheric conditions (Cabos et al. 2017). However, the atmosphere-ocean feedback is absent in the REMO simulation. With the prescribed sea surface conditions, the heat and moisture are provided continuously to the atmosphere, which induces relatively lower SLPs over the WNP (Fig. 8e) in the REMO simulation.

\section{Conclusions and discussion}

Previous studies have emphasized added values of the atmosphere-ocean coupling in many cases of climate modeling. However, there has been only a limited number of applications of the air-sea coupling to the regional climate modeling over East Asia. With the aim of studying the added effects of regional atmosphere-ocean coupling, the standalone atmospheric model REMO is compared with the coupled model ROM in simulating the East Asian summer monsoon (EASM) for the time period 1980-2012. In the ROM simulation, the boundary layers of atmosphere (REMO) and ocean (MPIOM) interact by exchanging momentum, heat, and water fluxes through the OASIS3 coupler. The two models are evaluated in terms of their ability to simulate the EASM, including the moisture transport, the atmospheric circulation, and the sea surface condition. The results are briefly summarized in Table 1 and elaborated as follows.

1. Both the REMO and ROM simulations resemble the observed pattern of summer precipitation over East Asia. The standalone REMO simulation is characterized by dry biases over the continent, but wet biases over the near-equatorial area from the Bay of Bengal to the western Pacific. With the atmosphere-ocean coupling, the ROM simulation represents summer precipitation well, especially over most of the continental area, but with significant underestimations over the western North Pacific (WNP). The ROM model simulates the EASM intensity better than the REMO model, with temporal correlation coefficients between the W-F indices extracted from the model results and observations higher by about 0.1 , whereas the REMO model tends to produce a stronger EASM.

2. In terms of the atmospheric circulation, the REMO and ROM simulations mainly differ in the lower and mid troposphere. REMO simulates stronger low-level westerlies extending too far eastward, which is associated with the South Asian summer monsoon (SASM) and leads to the convergence being shifted eastward to the WNP. Correspondingly, it produces a further eastward location of the western Pacific subtropical high (WPSH) at $500 \mathrm{hPa}$, with its western edge shifted to almost $150^{\circ} \mathrm{E}$. By contrast, the low-level flow and its convergence are reasonably represented in the ROM simulation, as well as the $500 \mathrm{hPa}$ geopotential height pattern. Regarding the
Fig. 10 Time series of the annual mean wind speed at $850 \mathrm{hPa}$ averaged over the subtropical $\operatorname{WNP}\left(110^{\circ}-145^{\circ} \mathrm{E}, 20^{\circ}-32^{\circ} \mathrm{N}\right)$ derived from the ROM (blue solid line) and REMO (red solid line) simulations for the time period 1980-2012

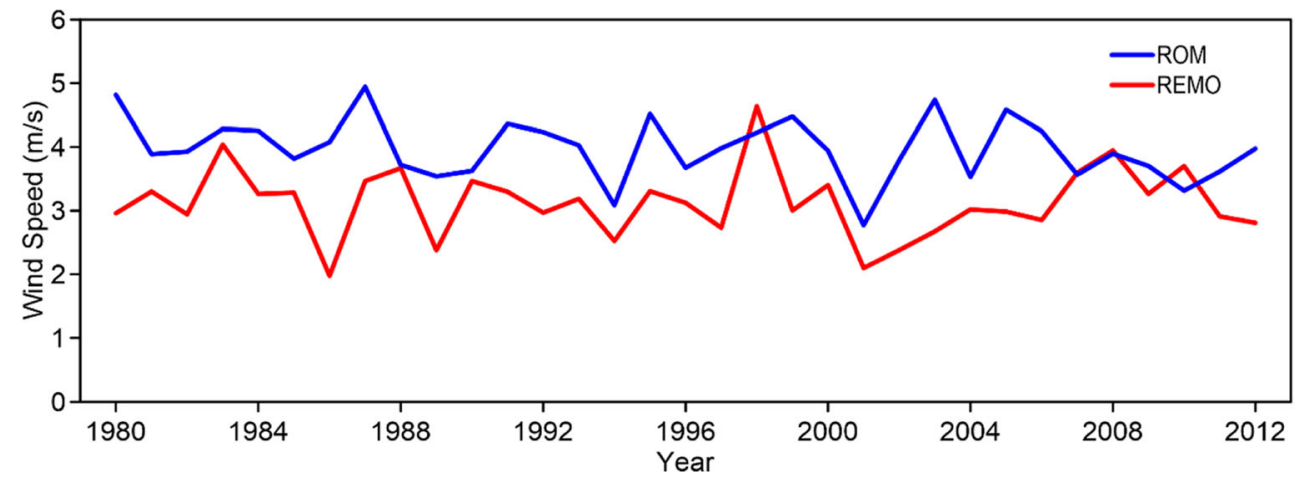


low-level specific humidity (at $850 \mathrm{hPa}$ ), the REMO simulation shows wet biases over most areas, which is in contrast to the dry bias over the WNP in the ROM simulation. Both models represent the South Asia High (SAH) circulation in the upper troposphere (at $200 \mathrm{hPa}$ ) well, with all the PCCs between the observations and the simulations greater than 0.99 , passing the 0.01 significance level. As a result, the pathways of the tropospheric vertically integrated moisture fluxes, which are mainly dominated by the low- to mid-tropospheric circulations and water vapor flow conditions, indicate similar structures to the wind flow patterns at $850 \mathrm{hPa}$ in both the REMO and ROM simulations. The simulated stronger precipitation over the ocean and the weaker precipitation over the East Asian continent from the standalone atmospheric model REMO could be attributed to the joint influence of the stronger low-level westerlies and the wetter lower troposphere. By contrast, ROM reproduces the low-level westerlies and the WPSH, which contributes to the representativeness on its modeling of the EASM.

3. With respect to the sea surface boundary layer, the ROM simulations are characterized by lower SSTs than the REMO results, which is due to mutual flux exchanges between the atmosphere and ocean from the intensified low-level winds over the subtropical WNP in the coupled model. As a consequence, an anomalous anticyclonic SLP is generated over the WNP, resulting in a more realistic distribution of SLP compared with the REMO simulation. The anomalous low-level anticyclone in the ROM simulation strengthens the WPSH and weakens the eastward-shifted low-level westerlies, improving the simulation of the low- and mid-level atmospheric circulations. Moreover, ROM produces less evaporation over the ocean due to the lower SSTs, inducing a drier lowlevel troposphere than the REMO simulation. By contrast, the higher SSTs in the REMO simulation with the prescribed sea surface conditions lead to a stronger SASMassociated low-level westerlies and an eastward shift of the WPSH, as well as a too wet low-level troposphere.

Concerning the regional climate model REMO, it has been shown that the model resolution greatly influences the simulation results (Xu et al. 2018). The higher horizontal resolution could bring about additional fine-scale weather processes in the REMO modeling over East Asia, particularly over areas with complex terrains (Xu et al. 2019). However, the standalone REMO model shows glaring deficiencies in simulating the EASM circulation owing to the inconsistencies at the air-sea interface, which need to be noted in climatology studies using this regional climate model in the atmosphereonly mode. Introducing atmosphere-ocean coupling effectively enhances the consistent interaction between the atmosphere 
over East Asia and the WNP ocean via cooling of the sea surface in the coupled ROM model, which, therefore, becomes a more skillful tool to reproduce the EASM system. In fact, previous experiments have also revealed the effective improvements in simulating the Asian monsoon system and its variability by regional air-sea coupling as a result of bias compensations (Singh et al. 2015; Zou and Zhou 2016; Yang et al. 2019). Enhancement of the air-sea interactions contributes to a substantially improved reproduction of the largescale climate characteristics in domains where atmospheric and oceanic factors are highly relevant (Lin et al. 2019). Further investigations on the dynamics with higher resolutions in the atmosphere and ocean models are essential to better understand the regional processes and the large-scale drivers of the regional climate.

Acknowledgments The anonymous reviewers are thanked for their constructive comments, which greatly improved this paper. We also thank Dr. Xiuhua Zhu and Dr. Torsten Weber for their extensive advices. We are grateful to ECMWF, NASA, and NOAA for access to their data products. The study was realized through access to the computing resources from the German Climate Computing Center (DKRZ).

Funding information The authors acknowledge the joint financial support of the National Key R\&D Program of China (Grant No. 2017YFC1502002), the National Natural Science Foundation of China (Grant Nos 41575104 and 41805056), the Postgraduate Research \& Practice Innovation Program of Jiangsu Province (Grant No. KYCX17 0875), the Scientific Research Foundation of CUIT (KYTZ201730), the Project Supported by Scientific Research Fund of Sichuan Provincial Education Department (18ZB0112), the Open Research Fund Program of KLME, NUIST (KLME201809), the PRIMAVERA project funded by the European Union's Horizon 2020 program (Grant Agreement No. 641727), the state assignment of FASO Russia (Theme Nos 0149-20180014 and 0149-2019-0015), and the China Scholarship Council (Nos 201608320193 and 201808510009).

\section{References}

Adler RF, Huffman GJ, Chang A, et al. 2003. The version-2 global precipitation climatology project (GPCP) monthly precipitation analysis (1979-present). J Hydrometeorol 4: 1147-1167. https://doi.org/ 10.1175/1525-7541(2003)004<1147:TVGPCP >2.0.CO;2

Asselin R (1972) Frequency filter for time integrations. Mon Weather Rev 100:487-490

Cabos W, Sein DV, Pinto JG, Fink AH, Koldunov NV, Alvarez F, Izquierdo A, Keenlyside N, Jacob D (2017) The South Atlantic anticyclone as a key player for the representation of the tropical Atlantic climate in coupled climate models. Clim Dyn 48:4051-4069. https://doi.org/10.1007/s00382-0163319-9

Cai D, You Q, Fraedrich K et al (2017) Spatiotemporal temperature variability over the Tibetan Plateau: altitudinal dependence associated with the global warming hiatus. J Clim 30:969-984. https://doi.org/ 10.1175/JCLI-D-16-0343.1

Cha D, Jin C, Moon J et al (2016) Improvement of regional climate simulation of East Asian summer monsoon by coupled air-sea interaction and large-scale nudging. Int J Climatol 36:334-345. https:// doi.org/10.1002/joc.4349
Dee DP, Uppala SM, Simmons AJ et al (2011) The ERA-Interim reanalysis: configuration and performance of the data assimilation system. Q J R Meteorol Soc 137:553-597

Fan Y, Fan K, Xu Z et al (2018) ENSO-South China Sea summer monsoon interaction modulated by the Atlantic Multidecadal Oscillation J Climate 31:3061-3076

Fan Y, Fan K, Zhu X et al (2019) El Niño-related summer precipitation anomalies in Southeast Asia modulated by the Atlantic Multidecadal Oscillation J Climate 32:7971-7987

Ge F, Zhi X, Babar ZA et al (2017) Interannual variability of summer monsoon precipitation over the Indochina Peninsula in association with ENSO. Theor Appl Climatol 128:523-531

Ge F, Zhu S, Peng T, et al. 2019. Risks of precipitation extremes over Southeast Asia: does $1.5^{\circ} \mathrm{C}$ or $2^{\circ} \mathrm{C}$ global warming make a difference? Environ. Res. Lett. 14: 044015

Gelaro R, McCarty W, Suárez MJ et al (2017) The modern-era retrospective analysis for research and applications, version 2 (MERRA-2). J Clim 30:5419-5454. https://doi.org/10.1175/JCLI-D-16-0758.1

Gent PR, Willebrand J, McDougall TJ, et al. 1995. Parameterizing eddyinduced tracer transports in ocean circulation models. J Phys Oceanogr 25: 463-474. https://doi.org/10.1175/1520-0485(1995) 025<0463:PEITTI >2.0.CO;2

Griffies SM. 1998. The Gent-McWilliams skew flux. J Phys Oceanogr 28: 831-841. https://doi.org/10.1175/1520-0485(1998)028<0831: TGMSF $>2.0 . \mathrm{CO} ; 2$

Hagemann S, Dümenil L (1997) A parametrization of the lateral waterflow for the global scale. Clim Dyn 14:17-31. https://doi.org/ $10.1007 / \mathrm{s} 003820050205$

Hagemann S, Gates LD (2001) Validation of the hydrological cycle of ECMWF and NCEP reanalyses using the MPI hydrological discharge model. J Geophys Res 106:1503-1510. https://doi.org/10. 1029/2000JD900568

Jacob D (2001) A note to the simulation of the annual and inter-annual variability of the water budget over the Baltic Sea drainage basin. Meteorog Atmos Phys 77:61-73. https://doi.org/10.1007/ s007030170017

Jacob D, Elizalde A, Haensler A et al (2012) Assessing the transferability of the regional climate model REMO to different coordinated regional climate downscaling experiment (CORDEX) regions. Atmosphere. 3:181-199. https://doi.org/10.3390/atmos3010181

Jacob D, Van den Hurk B, Andrae U et al (2001) A comprehensive model inter-comparison study investigating the water budget during the BALTEX-PIDCAP period. Meteorog Atmos Phys 77:19-43. https://doi.org/10.1007/s007030170015

Jungclaus JH, Fischer N, Haak H et al (2013) Characteristics of the ocean simulations in the Max Planck Institute Ocean Model (MPIOM) the ocean component of the MPI-Earth system model. J Adv Model Earth Syst 5:422-446. https://doi.org/10.1002/jame.20023

Kanamitsu M, Ebisuzaki W, Woollen J et al (2002) NCEP-DOE AMIP-II reanalysis (R-2). Bull Am Meteorol Soc 83:1631-1643. https://doi. org/10.1175/bams-83-11-1631

Kumar P, Kotlarski S, Moseley C et al (2015) Response of KarakoramHimalayan glaciers to climate variability and climatic change: a regional climate model assessment. Geophys Res Lett 42:18181825. https://doi.org/10.1002/2015GL063392

Kumar P, Podzun R, Hagemann S et al (2014) Impact of modified soil thermal characteristic on the simulated monsoon climate over South Asia. J Earth Syst Sci 123:151-160. https://doi.org/10.1007/s12040013-0381-0

Lee DK, Suh MS (2000) Ten-year east Asian summer monsoon simulation using a regional climate model (RegCM2). J Geophys Res 105: 29565-29577. https://doi.org/10.1029/2000JD900438

Lin R, Zheng F, Dong X (2019) The climatology and interannual variability of the East Asian summer monsoon simulated by a weakly coupled data assimilation system. Atmospheric and Oceanic Science Letters 12:140-146 
Liu B, Wu G, Mao J et al (2013) Genesis of the South Asian high and its impact on the Asian summer monsoon onset. J Clim 26:2976-2991. https://doi.org/10.1175/JCLI-D-12-00286.1

Lucas-Picher P, Christensen JH, Saeed F et al (2011) Can regional climate models represent the Indian monsoon? J Hydrometeorol 12:849868. https://doi.org/10.1175/2011jhm1327.1

Ludwig P, Pinto JG, Raible CC et al (2017) Impacts of surface boundary conditions on regional climate model simulations of European climate during the last glacial maximum. Geophys Res Lett 44:50865095. https://doi.org/10.1002/2017GL073622

Majewski D. 1991. The EUROPA-model of the Deutscher Wetterdienst. Proc. Seminar on Numerical Methods in Atmospheric Models. Reading, United Kingdom, ECMWF, 147-191

Marsland SJ, Haak H, Jungclaus JH, et al. 2003. The Max-PlanckInstitute global ocean/sea ice model with orthogonal curvilinear coordinates. Ocean Model 5: 91-127. https://doi.org/10.1016/S14635003(02)00015-X

Ngo-Duc T, Tangang FT, Santisirisomboon J et al (2017) Performance evaluation of RegCM4 in simulating extreme rainfall and temperature indices over the CORDEX - Southeast Asia region. Int $\mathrm{J}$ Climatol 37:1634-1647. https://doi.org/10.1002/joc.4803

Niederdrenk AL, Sein DV, Mikolajewicz U (2016) Interannual variability of the Arctic freshwater cycle in the second half of the twentieth century in a regionally coupled climate model. Clim Dyn 47:38833900. https://doi.org/10.1007/s00382-016-3047-1

Ninomiya K (1999) Moisture balance over China and the South China Sea during the summer monsoon in 1991 in relation to the intense rainfalls over China. J Meteor Soc Japan 77:737-751. https://doi. org/10.2151/jmsj1965.77.3 737

Paeth H, Born K, Girmes R et al (2009) Regional climate change in tropical and northern Africa due to greenhouse forcing and land use changes. J Clim 22:114-132. https://doi.org/10.1175/ 2008jcli2390.1

Paeth H, Müller M, Mannig B (2015) Global versus local effects on climate change in Asia. Clim Dyn 45:2151-2164. https://doi.org/ 10.1007/s00382-014-2463-3

Pinto JG, Gomara I, Masato G et al (2014) Large-scale dynamics associated with clustering of extratropical cyclones affecting Western Europe. J Geophys Res 119:13704-13719. https://doi.org/10.1002/ 2014JD022305

Roeckner E, Arpe K, Bengtsson L, et al. 1996. The atmospheric general circulation model ECHAM-4: model description and simulation of present-day-climate. Rep. 218. MPI für Meteorol. Hamburg, Germany

Roeckner E, Baeuml G, Bonaventura L, et al. 2003. The atmospheric general circulation model ECHAM 5. PART I: model description. Rep. 349. MPI für Meteorol. Hamburg, Germany

Sein DV, Koldunov NV, Pinto JG et al (2014) Sensitivity of simulated regional Arctic climate to the choice of coupled model domain. Tellus A. https://doi.org/10.3402/tellusa.v66.23966

Sein DV, Mikolajewicz U, Gröger M et al (2015) Regionally coupled atmosphere-ocean-sea ice-marine biogeochemistry model ROM: 1 . Description and validation. J Adv Model Earth Syst 7:268-304. https://doi.org/10.1002/2014MS000357

Simmons AJ, Burridge DM (1981) An energy and angular-momentum conserving vertical finite-difference scheme and hybrid vertical coordinates. Mon Weather Rev 109:758-766

Singh UK, Singh GP, Singh V (2015) Simulation skill of APCC set of global climate models for Asian summer monsoon rainfall variability. Theor Appl Climatol 120:109-122. https://doi.org/10.1007/ s00704-014-1155-6

Solman SA, Sanchez E, Samuelsson P et al (2013) Evaluation of an ensemble of regional climate model simulations over South America driven by the ERA-Interim reanalysis: model performance and uncertainties. Clim Dyn 41:1139-1157. https://doi.org/10.1007/ s00382-013-1667-2
Song F, Zhou T (2014) The climatology and interannual variability of East Asian summer monsoon in CMIP5 coupled models: does airsea coupling improve the simulations? J Clim 27:8761-8777. https://doi.org/10.1175/JCLI-D-14-00396.1

Steele M, Morley R, Ermold W (2001) PHC: a global ocean hydrography with a high-quality Arctic Ocean. J Clim 14:2079-2087

Uppala SM, Kållberg PW, Simmons AJ et al (2005) The ERA-40 reanalysis. Q J R Meteorol Soc 131:2961-3012. https://doi.org/10. 1256/qj.04.176

Valcke S, Caubel A, Declat D et al (2003) Oasis3 ocean atmosphere sea ice soil user's guide. CERFACS, Toulouse

Vondou DA, Haensler A (2017) Evaluation of simulations with the regional climate model REMO over Central Africa and the effect of increased spatial resolution. Int J Climatol 37:741-760. https://doi. org/10.1002/joc.5035

Wang B, Ding Q, Fu X et al (2005) Fundamental challenge in simulation and prediction of summer monsoon rainfall. Geophys Res Lett 32: L15711. https://doi.org/10.1029/2005GL022734

Wang B, Fan Z. 1999. Choice of South Asian summer monsoon indices. Bull Am Meteorol Soc 80: 629-638. https://doi.org/10.1175/15200477(1999)080<0629:COSASM>2.0.CO;2

Wang D, Liu Q, Huang RX et al (2006) Interannual variability of the South China Sea throughflow inferred from wind data and an ocean data assimilation product. Geophys Res Lett 33:L14605. https://doi. org/10.1029/2006GL026316

Webster PJ, Yang S (1992) Monsoon and ENSO: selectively interactive systems. Q J R Meteorol Soc 118:877-926. https://doi.org/10.1002/ qj. 49711850705

Xie P, Arkin PA. 1997. Global precipitation: a 17-year monthly analysis based on gauge observations, satellite estimates, and numerical model outputs. Bull Am Meteorol Soc 78: 2539-2558. https://doi. org/10.1175/1520-0477(1997)078<2539:GPAYMA>2.0.CO;2

Xu J, Koldunov N, Remedio ARC et al (2018) On the role of horizontal resolution over the Tibetan Plateau in the REMO regional climate model. Clim Dyn 51:4525-4542

Xu J, Koldunov N, Remedio ARC et al (2019) Downstream effect of Hengduan Mountains on East China in the REMO regional climate model. Theor Appl Climatol 135:1641-1658

Xue F, Zeng Q, Huang R, Li C, Lu R, Zhou T (2015) Recent advances in monsoon studies in China. Adv Atmos Sci 32:206-229. https://doi. org/10.1007/s00376-014-0015-8

Yang B, Zhang Y, Qian Y, et al. 2019. Better monsoon precipitation in coupled climate models due to bias compensation. npj Clim Atmos Sci 2: 43

Yang H, Zhi X, Gao J et al (2011) Variation of East Asian summer monsoon and its relationship with precipitation of China in recent 111 years. Agricultural Science \& Technology 12:1711-1716. https://doi.org/10.16175/j.cnki.1009-4229.2011.11.012

Zhang L, Fraedrich K, Zhu X et al (2015a) Interannual variability of winter precipitation in Southeast China. Theor Appl Climatol 119: 229-238

Zhang L, Sielmann F, Fraedrich K et al (2015b) Variability of winter extreme precipitation in Southeast China: contributions of SST anomalies. Clim Dyn 45:2557-2570

Zhu Q, He J, Wang P (1986) A study of circulation differences between East-Asian and Indian summer monsoons with their interaction. Adv Atmos Sci 3:466-477. https://doi.org/10.1007/BF02657936

Zhu S, Ge F, Fan Y et al (2020) Conspicuous temperature extremes over Southeast Asia: seasonal variations under $1.5^{\circ} \mathrm{C}$ and $2{ }^{\circ} \mathrm{C}$ global warming. Clim Change:1-18. https://doi.org/10.1007/s10584-01902640-1

Zou L, Zhou T (2013) Can a regional ocean-atmosphere coupled model improve the simulation of the interannual variability of the western North Pacific summer monsoon? J Clim 26:2353-2367. https://doi. org/10.1175/jcli-d-11-00722.1 
Zou L, Zhou T (2016) Future summer precipitation changes over CORDEX-East Asia domain downscaled by a regional oceanatmosphere coupled model: a comparison to the stand-alone RCM. J Geophys Res 121:2691-2704. https://doi.org/10.1002/ 2015JD024519

Zou L, Zhou T, Peng D (2016) Dynamical downscaling of historical climate over CORDEX East Asia domain: a comparison of regional ocean-atmosphere coupled model to stand-alone RCM simulations. J Geophys Res 121:1442-1458. https://doi.org/10.1002/ $2015 \mathrm{jd} 023912$
Zu T, Xue H, Wang D, Geng B, Zeng L, Liu Q, Chen J, He Y (2019) Interannual variation of the South China Sea circulation during winter: intensified in the southern basin. Clim Dyn 52:1917-1933. https://doi.org/10.1007/s00382-018-4230-3

Publisher's note Springer Nature remains neutral with regard to jurisdictional claims in published maps and institutional affiliations. 